\title{
ASSISTENCIA DE ENFERMAGEM AO PACIENTE PORTADOR DE BLASTOMICOSE SUL AMERICANA
}

* Laurinda Madureira Gandolla

** Lydia Pinheiro da Cruz

RBEn/04

GANDOLIA, L.M. e CRUZ, L.P. - Assistência de enfermagem ao paciente portador de blastomicose sul americana. Rev. Bras. Enf.; DF, $30: 254-261,1977$.

\section{INTRODUÇAO:}

$O$ alto indice depacientes portadores de Blastomicose Sul Americana na Unidade de Dermatologia, do Hospital das Clínicas da Universidade de Sāo Paulo despertou nosso interesse sobre 0 assunto.

Os leitos reservados para micoses, na maioria das vezes sāo ocupados por pacientes portadores de Blastomicose SulAmericana. Além dos pacientes internados, a unidade recebe diariamente pacientes do ambulatório, em regime de semi-internato, os quais recebem tratamento especifico por via parenteral. Um grupo freqüenta o Hospital às segundas, quartas e sextas-feiras, e outro às terças, quintas e sábados. Além disso, um dia por semana o ambulatório atende exclusivamente pacientes com esta moléstia.

\section{DEFINIÇÃO:}

A Blastomicose Sul-Americana (B.S.A.) é uma doença endêmica das zonas rurais, comum no Brasil.

A doença traz consigo, uma problemática social relevante, pois a faixa etária preferencialmente atingida é de 20 a 30 anos, justamente a época de maior produtividade do homem e de realizaçāo de vida. A prevençāo da moléstia é importante e faz parte das metas de governc, pois o desenvolvimento do país nāo prescinde do trabalho do homem do campo.

Como a doença é de evoluçāo crônica, impōe-se ao paciente um controle por tempo indeterminado e considerando o

- Supervisora de Enfermagem do Hospital das Clinicas de São Paulo.

* Enfermeira Chefe do Ambulatório de Alergia da Clínica Dermatológica do H.C. da F.M.U.S.P. 
GANDOLLA, L.M. e CRUZ, L.P. - Assistência de enfermagem ao paciente portador de blastomicose sul americana. Rev. Bras. Enf.; DF, 30 : 254-261, 1977.

nível sócio-cultural e econômico desses pacientes a Blastomicose Sul-Americana, constitui a nosso ver uma ordem para reflexão, uma vez que o tratamento é prolongado. Os constantes retornos do paciente ao Hospital representam um investimento negativo, interferindo na dinâmica dạ renda familiar do paciente e no domínio público, pois a doença tem seu preço. Além do mais, a doença deixa estigmas, que sobrepostos aos problemas já mencionados tornam-se sobremaneira cnerosos ao paciente.

A morbidade é conśiderável, devido à complexidade dos órgãos acometidos e à multiplicidade das lesōes no decorrer do processo evolutivo. No que se refere à letalidade, o êxito letal ocorre a longo prazo, por disseminação da doença que atinge órgãos nobres.

Para planejar a assistência de enferniagem temos que nos fundamentar nas características próprias do paciente e no estudo da doença. A doença é complexa e ao abordá-la procuramos o fazer de modo objetivo, não só relacionando - paciente à sua forma clínica, mas também procurando demonstrar a parte de assistência, da qual a enfermeira participa ativamente.

\section{Conceituação}

A Blastomicose Sul-Americana é uma doença de evoluçāo crônica, pertencendo à classe das micoses profundas; acomete a derme, a epiderme, as cartilagens, as articulaçōes e mais raramenta o sistema nervoso e os ossos. Produzindo lesōes granulomatosas do tipo destrutivo e desorganizado nos tecidos, ao regredir deixa sequelas. De início, as lesōes são geralmente cutâneas e mucosas, que constituem a porta de entrada às infecçōes, podendo haver contudo, concomitância de lesōes. $O$ paciente de um modo geral, quando procura assistência apresenta lesōes de vários tipos, em várias partes ou órgãos, geralmente por disse- minação. As principais formas e características de lesōes são:

\subsection{Forma Cutânea - Manifesta-se} em qualquer parte do corpo, poupando todavia, as regiōes plantares, porém atingindo o couro cabeludo; as lesōes generalizadas apresentam-se em formas de pápula tubérculo-túbero-ulcerosa, abscedante e lupoide.

1.2 Forma Mucosa - As lesōes podem aparecer isoladas ou haver concomitantemente lesōes cutâneas, ganglionares e viscerais. Na maioria dos pacientes, nota-se preferências de localização tais como, bochechas, lábios, língua, palato, amigdalas, laringe e faringe. Esta última com regular freqüência se estenosa, sendo necessário a indicação de traqueostomia como tratamento paliativo. Após o tratamento, as lesōes que cicatrizam, tornam-se fibrosadas, nacaradas e retráteis, que levam a atresia labial àa laringe e da faringe.

Ilustrando essa forma de localização citamos o paciente L.F.P., de 43 anos, procedente do Estado do Paraná. A retração fez desaparecer o lábio; ficanda em lugar uma cicatriz fibrosa; a abertura da boca reduziu-se, tornando-se insuficiente à introdução dos talheres. O paciente também é portador de lesōes faringeas.

Quando a localização é na mucosa oral, o paciente apresenta lesōes gengivais e peridentais. Nas lesōes peridentais, os dentes se tornam frouxos e há queda dos mesmos. Essas lesōes transformam profundamente a fisionomia do paciente, o levam a sérios distúrbios de nutrição, gerados pela dificuldade da irigestão de alimentos sólidos, merecendo atenção específica de enfermagem Todos os pacientes, com lesão oral, recebem assistência odontológica e otorrinolaringológica especializada, pois há tendência de propagação para os demais seguimentos orofaringeos. 
GANDOLLA, L.M. e CRUZ, L.P. - Assistência de enfermagem ao paciente portador de blastomicose sul americana. Rev. Bras. Enf.; DF, 30 : 254-261, 1977.

Freqüentemente os pacientes apresentam nas lesōes infecçōes secundárias e estado de decadência geral, causado não só pela doença em si, como também pelos problemas sócio-econômicos e emocionais existentes.

Como rotina de atendimento, o paciente ao ser admitido é submetido a testes. laboratoriais, exames de sangue, fezes, urina, $\mathrm{RX}$ de tórax e eletrocardiograma, estes últimos para detectar precocemente lesōes de pulmão e coração.

1.3 Forma ganglionar - No ínicio, quando ainda não há lesões, os gânglios se assemelham aos da moléstia de Hodgkin e da tuberculose ganglionar. Geralmente as manifestaçōes ocorrem ao nível dos gânglios cervicais e axiliares e mais raramente nos gânglios intraabdominais e inguinais. O gânglio se apresenta consistente, aumentado de volume e semelhante a um tumor; com a evolução, torna-se progressivamente amolecido, para finalmente ulcerar danco saída a secreção purulenta, espessa, de cor amarela característica, raramente hemorrágica e rica de parasitas. A forma ganglionar raramente se apresenta isolada, pois quase sempre é acompanhada de lesōes cutâneas, mucosas e viscerais.

Considerando os aspectos da doença, a confirmação do diagnóstico é feita através de exames bacteriológicos e micológicos especializados.

1.4 Forma generalizada ou visceral Quando há invasão das vísceras, o aparelho digestivo e o pulmão são os órgãos maís comumenue afetadas. No aparelho digestivo lesa o intestino grosso, apêndice, ceco e progressivamente evoluindo com caracteristicas de cronicidade, alcança o fígado. $O$ paciente refere queixas enterogástricas persistentes, semelhante às causadas por outras afecçöes gastroentéricas como: pirose, dor no estômago, indigestão e outros. A de- bilidade geral é progressiva até o êxito letal.

Estamos seguindo o paciente J.J.D.: lavrador proveniente do interior do Estado de São Paulo, com forma gástrica em evolução.

A afecção dos pulmōes geralmente ocorre por disseminação das lesōes das vias respiratórias superiores. Esta forma assume morbidade. No início o paciente apresenta queixas de um aparente resfriado e em seguida aparece a rouquidão. Estes sintomas vão evoluindo em caráter crônico, porém intenso, se agravando progressivamente e resistindo ao tratamento sintomático; pode confundirse com a tuberculose. A tosse que logo aparece, é acompanhada de expectoração abundante, semelhante a catarro, porém, menos densa e rica em agente etiológico. Continuando sua evolução mórbida, caminha o paciente para a debilidade orgânica geral, tornando-se progressivamiente caquético e como que consumido. Ao RX, a afecção assemelha-se à neoplasia pulmonar.

O paciente P.G.S., de 48 anos, procedente do interior do Estado de São Paulo, que está sendo acompanhado em rosso Serviço, teve lesão inicial na boca e está provavelmente com processo de disseminação para o pulmão.

Outras vísceras e órgãos como o baço, rins, pâncreas, aparelho reprodutor, podem ser atingidos na forma disseminada, apresentando as mesmas caracteristicas mórbidas já descritas. Por vezes 0) diagnóstico toma o nome do órgão atingido, por exemplo: blastomicose renal, blastomicose genital e outras. Nas supra-renais, a doença se manifesta, desencadeando Síndrome de Addison.

Em relação às lesōes do sistema nervoso, não temos casos em seguimento.

1.5 Forma óssea e cartilaginosa Quando a lesão atinge a cartilagem ou o osso, são dissiminadas por esses tecidos da cartilagem nasal e faringéia. 
GANDOLLA, L.M. e CRUZ, L.P. - Assistência de enfermagem ao paciente portador de blastomicose sul americana. Rev. Bras. Enf.; DF, 30 : 254-261, 1977.

para outras cartilagens e do maxilar superior para outros ossos.

1.6 Outras formas - A forma queloidiana, literalmente consta como de evolução mais benigna, em relação as demais.

Não é muito comum encontrarmos esta forma nos nossos pacientes, mas em seguimento, temos J.R.S., procedentee do Estado do Paraná, com lesão queloidiana no pavilhão auricular $\mathbf{E}$.

\section{Sinônimia}

Paracoccidioidomicose, granuloma paracoccidioidico.

\section{Etiologia}

O agente etiológico é um cogumelo dimorfo, o Paracoccidioides brasiliensís ou Blastomyces brasiliensis, que é uma variação do Blastomyces dermatitidis causador da Blastomicose Norte-Americuna.

\section{Transmissão}

Provavelmente pelo contato com o solo e vegetal contaminado. Geralmente, na entrevista, o paciente refere o hábito de mastigar capim, folhas vegetais silvestres, palitar os dentes com pequenos pedaços de galhos de arbustos, cheirar flores silvestres ou cultivar em áreas endèmicas. Há possibilidade da contaminação com verduras contaminadas, quando não lavadas adequadamente.

\section{Periodo de Incubação}

Não se sabe com precisão, porém é de se supor que seja de 7 a 14 dias.

\section{Prevalência}

t endêmica em toda a América do Sul, em especial no Brasil, nas áreas rurais. Incide com maior freqüência na faixa dos 20 aos 30 anos, mas pode ser encontrada em qualquer idade. Acomete mais aos homens do que as mulheres, provavelmente devido às maiores oportunidades de exposição ao fungo, se bem que no nosso Serviço, os leitos para mulheres estejam sempre ocupados.

$\mathrm{O}$ número de pacientes japoneses que procuram o nosso Serviço é considerável, pelo fato dos mesmos trabalharem no cultivo da terra em zonas rurais.

\section{Reservatório}

Tudo faz crer que seja a madeira, o solo e a vegetação, os principais reservatórios. Os cogumelos são encontrados na boca de pacientes aparentemente sadios, especialmente em torno dos dentes, sempre que os mesmos se encontrem com a moléstia incubada.

\section{Fonte de Infecção}

Provavelmente, a madeira, a poeira, o solo contendo esporos do Paracoccidioides brasiliensis.

\section{Transmissibilidade}

Não se verifica em condições naturais ce um para outro indivíduo diretamente. Provavelmente se transmite quando há lesão de continuidade da pele ou abrasōes por vezes imperceptíveis.

\section{Morbidade}

Pode ser considerada alta, tendo-se em conta os órgãos atingidos, o comportamento rebelde do paciente, as constantes recaídas e a necessidade de controle durante toda a sua vida.

\section{Letalidade}

Considerada alta, pois o processo evolui para o óbito, ainda que lentamente. 
GANDOLLA, L.M. e CRUZ, L.P. - Assistência de enfermagem ao paciente portador de blastomicose sul americana. Rev. Bras. Enf.; DF, 30 : 254-261, 1977.

\section{Resistência}

Desconhecida, assim como a suscetibilidade.

\section{Profilaxia}

Limitada pelo desconhecimento da suscetbilidade e resistência. primordial o controle dos contatos e do ambiente de origem. A desinfecção concorrente dos objetos contaminados e das secreções é indispensável, assim como a desinfecção terminal.

\section{Prognóstico}

Até o emprego das sulfas, a doença significava a expectativa do óbito. Ainda assim, é reservado, dada a impossibilidade de se localizar com segurança, focos profundos nos órgãos internos, e ainda considerando a ação invasora e destrutiva da moléstia.

\section{Diagnóstico}

f feito pelo exame clínico, e através de exames específicos de laboratório como a pesquisa direta, quando o exame micológico é realizado com material colhido da lesão. São empregados também métodos de coloração específica. Estes exames são feitos no laboratório especlalizado, anexo à Unidade.

\section{Tratamento}

O tratamento clínico é efetuado com sulfa lenta, pois a sulfa é droga especifica. Diante das dificuldades de detectar focos ocultos, mascarados ou silenciosos, a conduta terapêutica é a de excluir a possibilidade de foco e da sua persistência, o que só é possivel através de:

- Dose máxima tolerável da droga.

- Continuidade máxima tolerada pelo paciente. Todavia a conduta clínica busca a todo custo, impedir a resistência à droga pelo agressor e a intoxicação ou intolerância pelo paciente.

A cura geralmente é clínica, ficando o paciente indefinidamente sob controle.

Exemplificando, citamos L.J.R., de 64 anos, procedente do Estado de São Paulo, em seguimento ambulatorial com lesões orofaringéias, já passou pela sexta internação e A.P., de 22 anos, procedente do Estado de Minas Gerais, já passou pela $15 .^{a}$ internação. Quando o paciente se torna resistente ao tratamento, essa resistência assume caráter definitivo a todas as sulfas.

Ocasionalmente 0 paciente pode necessitar de intervenção cirúrgica. Quando a retração cicatricial, do lábio, face, nariz e outras, oferecem possibilidade, é feita correção pela cirurgia plástica, e nos pacientes com estenose traqueal recorre-se à traqueostomia.

\section{Assistência de Enfermagem}

Conhecidos, o paciente e a doença, concluímos que a ação da enfermagem $\dot{e}$ de grande alcance em todas as fases da moléstia: diagnóstico, tratamento ambulatorial, tratamento em regime de internação e orientação após cada alta. Os pacientes sentem muita necessidade de apoio devido sua tendência em se isolar dos demais, introverte-se e deprime-se, em especial quando suas lesões afetam a auto-imagem.

Para demonstrar o quanto eles dependem dessa ação contínua, citaremos novamente L.M. Este, matriculou-se para tratamento no Hospital das Clínicas em 1950 - quando contava apenas 24 anos de idade. Foi tratado, à base de sulfa lenta até 1963. Iniciou tratamento com Anfotericina B, nessa data, devido ao estacionamento do processo. Durante a fase de tratamento, teve periodos de melhora e piora da sintomatologia. Em 
GANDOLLA, L.M. e CRUZ, L.P. - Assistência de enfermagem ao paciente portador de blastomicose sul americana. Rev. Bras. Enf.; DF, 30 : 254-261, 1977.

1970 necessitou ser traqueostomizado de urgência devido à dificuldade respiratória. Sua última internação, em $26 / 06 / 75$, foi devida principalmente ao agravamento de suas condiçōes respiratórias. Continuou o tratamento especifico com Anfotericina B três vezes por semana e medicação sintomática para outras queixas que apresentava. Melhorou um pouco do quadro respiratório mas em outubro piorou novamente, apresentando grande quantidade de secreção catarral de odor fétido pela traqueostomia. Apresentava-se dispnêico não podendo dispensar a administração contínua de oxigênio.

Psicologicamente piorou, passando por estado de depressão e revolta contra a doença e o meio. Suas queixas eram múltiplas e continuas: o médico não lhe dava atenção, não conversava com ele, não mudava sua prescrição; a dieta não lhe agradava e nem o suco para hidratação; insistia em sair da cama na hora do repouso, preocupava-se com o filho cujo casamento se aproximava e ele não se encontrava em condiçōes de orientálo. Nesta fase apresentou idéias de autodestruição. As ações da enfermagem foram sempre as de atender suas necessidades básicas afetadas sob o ponto de vista físico, psicológico e social.

A necessidade de $\mathrm{O}_{2}$ então prioritária foi atendida através da vigilância da respiração, da aspiração de secreçōes, sempre que necessário e administração contínua de $\mathrm{O}_{2}$ pela cânula.

O cuidado corporal e conforto físico fol mantido através de banhos no leito, massagens nos pontos de apoio e mudanças de decúbito.

A manutenção da mecânica corporal através de bom posicionamento dos membros inferiores em especial durante as mudanças de decúbito. Sob o ponto de vista de atender suas necessidades de nutrição, houve sempre entrosamento com a nutricionista que modificava as dietas, com o objetivo de melhorar a sua aceitação.

As necessidades psico-sócio-espirituais foram atendidas procurando-se que tivesse assistência freqüente do capelão; era estimulado para assistir programas de TV em suas fases de melhora; e procurou-se integrá-lo ao ambiente que dividia com outros pacientes. Suas visitas foram liberadas podendo recebê-las a qualquer hora do dia, e foi-lhe permitido a presença de acompanhante. Foi encaminhado à assistente social em todas as situações que dela dependiam.

$A$ ação da enfermagem se modificava à medida que novas situações se apresentavam, como por exemplo, em sua crise depressiva no final de outubro, quando se recusava a conversar: manifestava-se inseguro pela aproximação do dia de Finados, pois relacionava seu estado ao dia dos mortos.

Assim a prioridade de ação da enfermagem foi a de estimulá-lo a esperar por dias melhores como os que já tinha tido anteriormente, e a continuar com o tratamento, pois nessa fase tinha intenção de abandoná-lo. Foi piorando progressivamente vindo a falecer no dia 09/12/75 com apenas 49 anos de idade e após 165 dias da internação.

$\mathrm{Na}$ mesma situação de L.M. temos outros pacientes cujos prognósticos são fechados e que são dependentes da ação de uma equipe multiprofissional bem integrada.

\section{CONCLUSĀO}

Nos sentimos preparados para essa ação, planejando os cuidados, estabelecendo prioridades e utilizando os recursos disponiveis de forma que a assistência prestada seja integral. 
GANDOLLA, L.M. e CRUZ, L.P. - Assistência de enfermagem ao paciente portador de blastomicose sul americana. Rev. Bras. Enf.; DF, 30 : 254-261, 1977.

\section{BIBLIOGRAFIA}

1. BECCHELLI, L. \& CURBAN, G. V. Compêndio de Dermatologia - 4." ed - São Paulo, Atheneu, 1975, p. 271281.

2. DEL NEGRO, G. - Localização suprarenal da Blastomicose Sul-Americana - São Paulo - 1961 (Tese de doutoramento apresentada na 22. $\mathrm{Ca}$ deira de Doenças Tropicais e Infecciosas na Faculdade de Medicina da Universidade).

3. FONSECA, J. B. - Blastomicose SulAmericana; Estudo das lesōes dentárias e paradentárias sob o ponto de vista clínico e histopatológico São Paulo, 1957 (Tese de doutora- mento apresentada na $1 .^{\mathrm{a}}$ Cadeira de Clínica Odontológica, na Faculdade da Farmácia Odontológica da Universidade de São Paulo.

4. PROFILAXIA das doenças transmissiveis. New York, Associação Americana de Saúde Pública, 1962.

5. SAMPAIO, S.A. P.\& CASTRO, R. M. Dermatologia Básica - São Paulo Estudo e Pesquisas Ltda., 1970 Cap. XXV, p. 156-159.

6. VERONESI, R., - Doenças Infecciosas e Parasitárias - 5." ed., 1972 - Editora Guanabara Koogan S.A., Rio de Janeiro - Blastomicose SulAmericana - p. 773-784. 
GANDOLLA, L.M. e CRUZ, L.P. - Assistência de enfermagem ao paciente portador de blastomicose sul americana. Rev. Bras. Enf.; DF, 30 : 254-261, 1977.

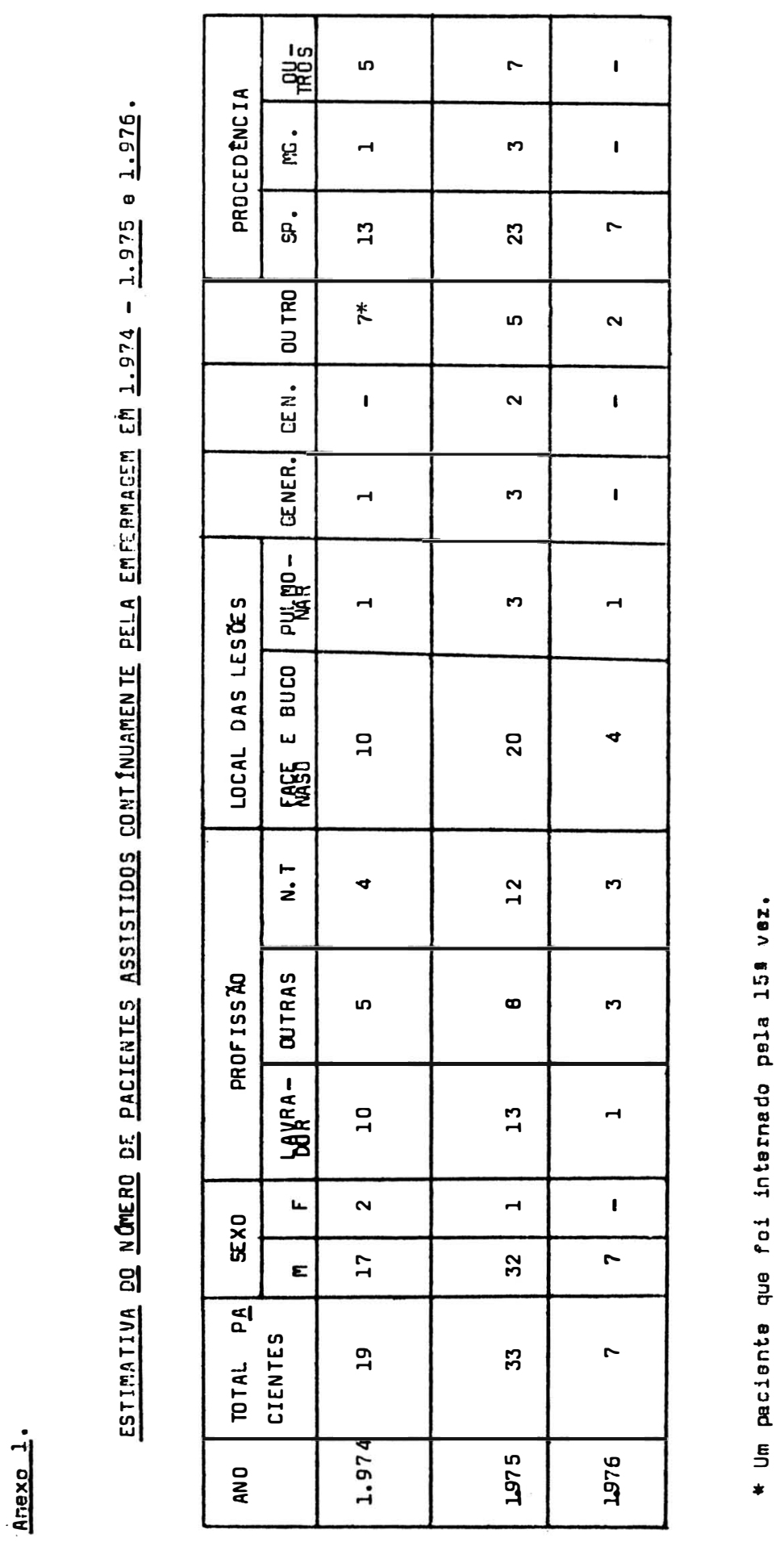

